\title{
Evaluation of Ethiopian Durum Wheat Varieties and Landrace Cultivars for the Adult Plant Resistance of Wheat Leaf Rust
}

\section{(Puccinia triticina)}

\author{
Habtamu Tesfaye Ayehu \\ Ethiopian Institute of Agricultural Research Institute (EIAR), \\ Debre-zeit Agricultural Research Center (DZARC), P.O.Box 32. \\ Debre-zeit, Ethiopia
}

\begin{abstract}
Wheat Leaf rust caused by the pathogen Puccinia triticina is a serious threat of wheat production in Ethiopia, yield loss due to this disease reached up to 70\%. A study was carried out to identify leaf rust adult plant resistance in commercial durum wheat cultivars and landraces. 35 durum wheat Varieties and 200 durum wheat landraces with three susceptible checks arranged in Augment design and evaluated against leaf rust at Debere Zeit Agricultural Research Center, Ethiopia during the 2017/18 main season. Terminal Rust Severity (TRS), Coefficient of Infection (CI), Area under Disease Progress Curve (AUDPC) and Disease Progress Rate (DPR) were used to measure leaf rust adult plant resistance in the test materials. Analysis of all disease parameters was carried out using SPAD software. There were highly significant differences $(P<0.01)$ for all disease parameters among the test cultivars. Above half of evaluated Varieties and landraces (57.9\%) showed better Adult plant resistance under high disease pressure. From the total of 235 tested Varieties and landraces, 136 had slow rusting resistance of which 14 were released varieties and the rest 122 were landraces. Four commercial Varieties (Selam, Mossobo, Bekelcha, and Utuba) and a landrace cultivar (Mcd4-32) had high levels of field resistance with very low AUDPC, ACI, and TRS with MR infection type; hence, they may carry major resistance gene (s). However, the rest 99 Varieties and landraces exhibited high to moderate level of slow rusting resistance with MS responses and may have adult plant resistance controlled by minor resistance genes. The slow rusting cultivars identified from the current study can be used for further manipulation in wheat improvement programs.
\end{abstract}

Keywords: Adult plant resistance, Durum wheat, Leaf rust, Puccinia triticina.

\section{INTRODUCTION}

Wheat is staple food crops that provide $20 \%$ of protein and calories for human consumption worldwide [1]. The demand for wheat is projected to grow over the coming decades [2]. However, World wheat productivity is growing at $1 \%$ rate.

Wheat is important crops in Ethiopia, represent $14 \%$ of caloric intake, i.e. second important food crop [1]. In area of cultivation, fourth crop in Ethiopia [3]. In rapidly urbanizing Sub-Saharan Africa, wheat consumption is expected to grow by $38 \%$ by 2023 [4]. Demand steadily increased in Ethiopia particularly due to the emergence of many food processing industries [3].

Use of crop diversity is a key approach to improve productivity and achieve food security [5]. Ethiopian durum wheat landraces are diverse and possess high variation but not exploited [6]. Ethiopian landraces contributed to world wheat improvement for instance, the Ethiopian durum wheat landrace ST464 was one of the major sources of Sr13 [7]. In Ethiopia, more than 90 bread and 36 durum wheat varieties have been released for production since 1950s. However, the national average yield is still $2.78 \mathrm{t} / \mathrm{ha}$, which is far less than potential yields of 8 to $10 \mathrm{t} / \mathrm{ha}$ [8].The average yield of durum wheat is even less i.e. $1.3 \mathrm{t} / \mathrm{ha}$. The low productivity is attributed to lack of resistant varieties to the prevalent wheat rusts. 
Leaf rust, caused by Puccinia triticina has been one of the most important diseases in Ethiopia [9]. Leaf rust is important disease, especially on durum wheat, losses reaching up to $70 \%$ on susceptible cultivars [10-12,]. In Ethiopia, most of the research works on wheat diseases have been focused on yellow and stem rusts. Research works on host pathogen interactions in durum wheat to leaf rust pathogen are limited. Thus, identification of resistance sources from durum varieties and landraces would be essential for resistance breeding and variety deployment. Therefore, the objective of the study was: Identify sources of adult plant resistance for leaf rust in Ethiopian durum wheat varieties and landraces.

\section{MATERIALS AND METHODS}

\subsection{Descriptions of the Study Area}

The experiment was conducted in a black soil at Debre Zeit Agricultural Research Center, Ethiopia. Debre Zeit is located in East Shewa Administrative Zone of the Oromia National Regional State $47 \mathrm{~km}$ southeast of Addis Ababa, at 38 57' E longitude and $08^{\circ} 44^{\prime} \mathrm{N}$ latitude, with an elevation of 1900 m.a.s.l [13]. It receives an annual average rainfall of $851 \mathrm{~mm}$, and has an annual temperature range of $8.9-28.3{ }^{\circ} \mathrm{C}$, with $61.3 \%$ mean annual relative humidity [15].

\subsection{Planting Materials}

A total of 200 durum wheat landraces, 35 durum wheat varieties, and 3 susceptible checks used for adult plant resistance against leaf rust at Debre zeit during 2017/18 main season. The planting materials obtained from Debre zeit Agricultural Research Center. The 35 durum wheat varieties released in Ethiopia from 1976 to 2015. The susceptible checks were Morocco (bread wheat), Local Red, and Arendeto (both durum wheat).

\subsection{Plot Size and Design}

The experiment was arranged in an augmented design, and each plot consists of two rows with plot size of $1 \mathrm{~m} \times 0.2 \mathrm{~m}$ and with a spacing of $0.4 \mathrm{~m}$ between plots and $1 \mathrm{~m}$ between blocks. Seeding rate, fertilization, weeding and other management practices applied according to the recommendations for the area. To ensure uniform spread of inoculum and for sufficient disease development during the trial periods, the susceptible wheat cultivar 'Morocco' was planted a week earlier around the experimental areas. Artificial inoculation was carried out by spraying a mixture of leaf rust spores suspended in mineral oil [16].

\subsection{Data Collection and Analysis}

Disease severity was scored by estimating the approximate percentage of leaf area affected using modified Cobb scale [14]. Disease severity recorded from all plots six times in 10-days interval starting from the onset of leaf rust on the susceptible checks. The host plant responses (infection types) scored according to [16].

Average coefficient of infection (ACI) calculated by multiplying the percentage severity and the constant value assigned to each reaction type [17]. The constant values were considered as $\mathrm{R}$ (Resistant) $=0.2$, MR (moderately resistant) $=0.4, \mathrm{M}$ (intermediate) $=0.6$, MS (moderately susceptible $)=0.8$ and $\mathrm{S}$ ( susceptible $)=1$.

The area under the disease progress curve (AUDPC) for each plot calculated from the multiple leaf rust severity scorings. Area under disease progress curve (AUDPC) calculated using the formula suggested by [17].

$$
A U D P C=\sum_{i=1}^{n-1}\left(\left(\frac{x_{i}+x_{i}+1}{2}\right)\left(t_{i}+1-t_{i}\right)\right)
$$

Where, $x i=$ the disease severity of $i^{\text {th }}$ record, $X_{i}+1=$ the disease severity of $i+1^{\text {th }}$ record and $t_{i}+1-t i=$ Number of days between the $i^{\text {th }}$ record and $i+1^{\text {th }}$ record, and $n=$ number of observations.

Disease progress rate (DPR) as a function of time was calculated from disease severity observations by using Gompertz model adopted by Van der Plank (1963). dy/dt $=$ yo $+\mathrm{rGt}$ where dy/dt $=$ absolute disease rate $\mathrm{rGt}=$ rate of infection, yo $=$ amount of disease. Each severity data were transformed to $-\ln [-\ln ($ yo) $]$, where $\ln =\operatorname{lan}$, yo = disease severity in decimal form for each observation time.

The coefficient of infection (CI), terminal rust severity (TRS), Area under disease progress curve (AUDPC), and Disease progress rate (DPR) were analyzed using SPAD software [18]. Means that differ significantly separated using critical difference in each 
category viz., checks, test entries, tests and checks. Correlation analysis was made among the different disease parameters (TRS, AUDPC, ACI, and DPR).

\section{RESULT AND DISCUSSIONS}

\subsection{Analysis of Variance}

The analysis of variance (ANOVA) for different leaf rust resistance parameters is shown in Table 1. There was highly significant $(\mathrm{p}<0.01)$ difference among the test materials for all slow rusting parameters. In separate comparison of test cultivars Vs checks the analysis of variance showed highly significant $(\mathrm{P}<0.01)$ differences for all parameters. The test cultivars have also showed highly significant $(\mathrm{p}<0.01)$ difference for all parameters. There were highly significant difference $(\mathrm{p}<0.01)$ among the check cultivars for all slow rusting parameters. Selection of genotypes for slow rusting resistance is possible, because genotypes were significantly different.

Table 1. Mean Squares of Slow Rusting Parameters

\begin{tabular}{|l|l|l|l|l|}
\hline \multirow{2}{*}{ Mean Squares } & \multicolumn{3}{|c|}{ Slow rusting parameters } \\
\cline { 2 - 5 } & TRS & ACI & AUDPC & DPR \\
\cline { 2 - 5 } & & & & \\
\hline Block (12) & $75.5 \mathrm{NS}$ & $59.8^{* *}$ & $1480442^{* *}$ & $0.004 \mathrm{NS}$ \\
\hline Treatments(271) & $163.8^{* *}$ & $114.3^{* *}$ & $215910^{* *}$ & $0.0053^{* *}$ \\
\hline Checks(3) & $2302.8^{* *}$ & $1607.4^{* *}$ & $3349483^{* *}$ & $0.00064^{* *}$ \\
\hline Test cultivars (235) & $124.5^{* *}$ & $82.8^{* *}$ & $155837.5^{* *}$ & $0.0054^{* *}$ \\
\hline Test cultivars and checks (238) & $5062.1^{* *}$ & $4506.1^{* *}$ & $8022937.9^{* *}$ & $0.0055^{* *}$ \\
\hline Error & 54.3 & 14.5 & 35140.4 & 0.00024 \\
\hline CV (\%) & 14.7 & 13.2 & 11.7 & 4.9 \\
\hline
\end{tabular}

$* *=$ highly significant $(\mathrm{p}<0.01), \mathrm{NS}=$ non-significant, $\mathrm{TRS}=$ terminal rust severity, $\mathrm{ACI}=$ average coefficient of infection, $\mathrm{AUDPC}=$ area under disease progress curve, $\mathrm{DPR}=$ disease progress rate, $\mathrm{CV}=$ coefficient of variation.

\subsection{Terminal rust severity}

There was wide variation in the leaf rust terminal rust severity ranging from 10 to $70 \%$. Diverse host reactions also observed ranging from resistance $(\mathrm{R})$ to Susceptible (S).Terminal rust severity represents the cumulative result of all resistance factors during the progress of epidemics [19]. Based on terminal rust severity the tested durum wheat cultivars were grouped in to three groups of slow rusting resistance, that is high, moderate, and low level of resistance, having 1-30, 31-50\% and above 50\% respectively [20].

Despite the heavy leaf rust disease pressure, 25 tested durum wheat cultivars namely; Megenagna, Selam, Mossobo, Bekelcha, Utuba, Mcd3-19, Mcd4-32, Mcd4-11, Mcd4-12, Mcd4-28, Mcd5-35, Mcd7-42, Mcd8-45, Mcd8-10, Mcd10-9, Mcd10-6, Mcd11-9, Mcd11-31, Mcd11-18, Mcd12-5, Mcd13-34, Mcd15-38, Mcd15-27, Mcd16-4 and Mcd16-50 exhibited high level of slow rusting resistant with moderately susceptible to moderately resistance response. Genotypes with slow rusting resistance are greatly important to achieve effective breeding for durable resistance to leaf rust [21 and 22]. According to [21], the availability of resistance genes in the genotypes overcome the prevailed virulence leaf rust pathogens in the field and led to statistically low disease severity, despite the compatible host pathogen reactions. Previously, [23, 24, 20, and 26] used terminal rust severity to evaluate slow rusting in wheat cultivars.

On the other hand, 171-durum wheat cultivars showed terminal rust severity between 31 and $50 \%$, of these 20 were released wheat varieties and 151 were landraces and were regarded as possessing moderate level of slow rusting resistance. The rest 39 cultivars, of these 10 released varieties and 29 landraces exhibited above 50\% Terminal rust severities, which had no slow rusting resistance. From the three susceptible checks Arendeto was not demonstrate susceptibility while Morocco and Local red displayed the highest disease severities of 70 to $80 \%$ with completely susceptible responses, indicating that an acceptable epidemic pressure was established. 
International Journal of Advances in Scientific Research and Engineering (ijasre), Vol 5 (2), February-2019

Table 2. Durum Wheat Cultivars Having Adult Plant Resistance

\begin{tabular}{|l|l|l|l|l|l|l|}
\hline S. No & \multirow{2}{*}{ Cultivars } & \multicolumn{1}{|c|}{ Pedigree } & ACI & TRS & rAUDPC & DPR \\
\hline $\mathbf{1}$ & Mossobo & BHA/u/nv//2*'E\#24 & 5.3 & 20 & 20.3 & 0.015 \\
\hline $\mathbf{2}$ & Bekelcha & 98OSNGedilfa/Guerou & 6 & 30 & 22.3 & 0.079 \\
\hline $\mathbf{3}$ & Selam & 61130/Lds//G11's'/3/cit's'/4/Hora/3/Megrbce's' & 3.3 & 30 & 22.4 & 0.079 \\
\hline $\mathbf{4}$ & Utuba & Omruf1/Stojocri2/3/1718/BreadWheat24//Karim & 5.3 & 20 & 20.3 & 0.015 \\
\hline $\mathbf{5}$ & Megenagna & $\begin{array}{l}\text { Dz04-1167/Dz129/yemen/cit's'/pls's'/3/ } \\
\text { TaganrogB.B/4/5/chen's'/RCHI//Hui's'/BHA }\end{array}$ & 8.6 & 20 & 20.3 & 0.015 \\
\hline $\mathbf{6}$ & $\mathbf{M c d 4 - 3 2}$ & Landrace & 5.3 & 30 & 22.3 & 0.015 \\
\hline $\mathbf{7}$ & $\mathbf{M c d 7 - 4 2}$ & Landrace & 6.7 & 30 & 19.3 & 0.27 \\
\hline $\mathbf{8}$ & $\mathbf{M c d 4 - 1 2}$ & Landrace & 8.3 & 30 & 29.5 & 0.28 \\
\hline $\mathbf{9}$ & Morocco & Susceptible check & 43 & 63 & 90.3 & 0.31 \\
\hline
\end{tabular}

$\mathrm{ACI}=$ Average Infection coefficient, $\mathrm{TRS}=$ Terminal rust severity, $\mathrm{rAUDPC}=$ relative Area under disease progress curve, $\mathrm{DPR}=$ Disease progress rate.

\subsection{Coefficient of infection}

The data on disease severity and host reaction were combined to calculate coefficient of infection (CI). According to [27] cultivars with coefficient of infection values of 0-20, 21-40, and 41-60 regarded as possessing high, moderate, and low level of slow rusting resistance respectively. In this study, 17 durum wheat cultivars (Cocorit-71, Gerardo, LD-357, Foka, Kilinto, Tob-66(Arsi robe), Ginchi, Yerer, Megenagna, Selam, Mossobo, Ejersa, Bekelcha, Obsa, Flakit, Mangudo, Utuba) and 31 landraces (Mcdl-23, Mcd1-43, Mcd1-12, Mcd2-12, Mcd3-19, Mcd4-32, Mcd4-50, Mcd4-11, Mcd4-12, Mcd4-28, Mcd7-42, Mcd8-45, Mcd8-10, Mcd10-9, Mcd10-44, Mcd10-6, Mcd10-4, Mcd10-14, Mcd11-9, Mcd11-31, Mcd11-18, Mcd12-30, Mcd12-5, Mcd13-34, Mcd1420, Mcd15-38, Mcd15-8, Mcd15-15, Mcd15-27, Mcd16-4 and Mcd16-50) exhibited average coefficient of infection(ACI) values between 0 and 20. Therefore, these genotypes are considered to have slow rusting resistance.

On the other hand, 133 durum wheat varieties and landraces had ACI value of 21 to 40 designated as having moderate levels of slow rusting resistance. However, the rest 57 durum wheat varieties and landraces including the susceptible checks had ACI values of more than 40. Similarly, [28] and [12] appraised slow rusting resistance to wheat leaf rust with coefficient of infection and reported the presence of different adult plant resistance conferring genes in wheat cultivars.

\subsection{Area under disease progress curve (AUDPC)}

Disease progress curve is a better indicator of disease expression over time [29]. Therefore, selection of cultivars having lower AUDPC value is acceptable for practical purposes. Based on the AUDPC value the tested wheat cultivars categorized in to three distinct groups for slow rusting resistance. Cultivars exhibited AUDPC value up to $30 \%$ of the check were grouped as having high level of partial resistance, while those cultivars having AUDPC values up to $70 \%$ of the check were grouped as moderately resistance cultivars and cultivars having above $70 \%$ of the check were grouped as susceptible cultivars [27].

In this study, five wheat cultivars (Megenagna, Selam, Mossobo, Bekelcha, and Utuba) and four landraces (Mcd3-19, Mcd4-32, Mcd4-12, and Mcd7-42) showed rAUDPC values lower than 30. Of these Megenagna, Mcd3-19, Mcd4-12, and Mcd7-42 showed moderately susceptible (MS) response and the rest showed moderately resistance (MR) responses. According to [30, 31 and 32], genotypes that had MS infection type and low AUDPC might carry genes conferring durable resistance. These types of genotypes first shown rust infection characterized by chlorotic and necrotic lesions; subsequently the disease progression remained slower and highly retarded. Such partially resistant cultivars could highly delay evolution of new virulent races of the pathogen because multiple point mutations are extremely rare in such circumstance [33 and 34].

On the other hand, Selam, Mossobo, Bekelcha, Utuba, and Mcd4-32 showed MR responses. The moderately resistance on this cultivars could be because of hypersensitive responses; such type of resistance often breaks down due to the development of new races of the pathogen. Suitable breeding strategies like direct transfer of these resistance genes through backcrosses used to develop resistance varieties in durum wheat breeding program.

From the tested durum wheat genotypes, 152 displayed relative AUDPC values of $70 \%$ when compared to the susceptible checks $(100 \%)$. Of these, 24 were released cultivars while 128 were durum landraces and these genotypes are considered possessing moderate level of slow rusting resistance. The rest 74 genotypes showed rAUDPC value above $70 \%$ of the checks and were 
considered as susceptible. Other researchers have also reported variation in AUDPC among different wheat cultivars and genotypes with lower AUDPC values considered to have slow rusting resistance to leaf rust [12 and 35].

\subsection{Disease progress rate}

Slow rusting resistance is characterized by a reduced rate of epidemic development despite a compatible host pathogen interaction [22 and 19].Therefore, cultivars having lower disease progress rate are acceptable for practical purpose.

The maximum disease progress rate observed on the cultivar Malefia while, the minimum were on cultivar Mossobo and Megenagna. Cultivars Megenagna, Selam, Mossobo, Bekelcha, Utuba, and Mcd4-32 showed low disease progress rate per unit time. Disease progress rate of few cultivars (Malefia, Leliso, Mcd5-50 and Mcd3-25) were more than the susceptible cultivars, due to the fact that disease scoring was started when disease severity was already observed in certain level on the susceptible checks. Hence, the actual infection rate for susceptible checks may even be more but minimal green tissue was available.

Gompertz model was used to describing the rate of leaf rust infection. The coefficient of determination $\left(\mathrm{R}^{2}\right)$ was higher for Gompertz model. Based on Gompertz model the regression equation used to describe the rate of leaf rust progress was not significant for all cultivars, except for susceptible cultivars apparently because of low disease development per unit day on slow rusting cultivars. The coefficient of determination was low for each slow rusting cultivar. However, in most susceptible cultivars the disease progress rate was significance $(0.05 \%)$. Generally, variation in wheat leaf rust disease progress rate due to the resistance level of the cultivars was clearly observed. Wheat leaf rust was increasing more rapidly on susceptible cultivars than slow rusting cultivars.

\subsection{Correlations of between slow rusting resistance parameters of leaf rust}

Table 3: Correlations among leaf rust resistance parameters in durum wheat genotypes

\begin{tabular}{lllll}
\hline Parameters & TRS & ACI & AUDPC & DPR \\
\hline TRS & $0.84^{* *}$ & & & \\
ACI & $0.83^{* *}$ & $0.97^{* *}$ & & \\
AUDPC & $0.47^{* *}$ & $0.49^{* *}$ & $0.50^{* *}$ & \\
DPR & & &
\end{tabular}

** =significant level at $\mathrm{P}<0.01$, TRS=Terminal rust severity, $\mathrm{ACI}=$ Average coefficient of infection, $\mathrm{AUDPC}=$ Area under disease progress curve, DPR= Disease progress rate.

A positive and strong correlation of TRS with AUDPC $r=0.83(p<0.01)$ and ACI $r=0.84(p<0.01)$ was found, while TRS with DPR showed weak positive correlation $\mathrm{r}=0.47(\mathrm{P}<0.01)$. ACI with AUDPC also showed strong positive correlation $\mathrm{r}=0.97$ $(\mathrm{P}<0.01)$, but ACI with DPR showed weak positive correlation $\mathrm{r}=0.49(\mathrm{P}<0.01)$. AUDPC and DPR also showed weak positive correlation $\mathrm{r}=0.50(\mathrm{P}<0.01)$.

A strong positive correlation of all slow rusting parameters except Disease progress rate agreed with the result of [33, 35, and 36]. Although positive correlations were obtained between Disease progress rate and other slow rusting parameters, the relationship between the variables were weak, this indicates that the rate of infection reduce as epidemic progressed because less healthy tissue was available for additional infection [37].

Since TRS, ACI and AUDPC had strong positive correlations; selection of cultivars having terminal rust severity less than 30\%, ACI between 0 to 20 and AUDPC less than 30\% is normally accepted for practical purpose [27, 35, and 25]. Feasibility of measuring slow rusting resistance under field condition preferably by low terminal rust severity and infection coefficient has been reported by [25]. [38] also reported field selection for the slow rusting resistant preferably by low AUDPC value.

Accordingly, durum wheat cultivars Namely; Megenagna, Selam, Mossobo, Bekelcha, Utuba,Mcd4-32, Mcd4-12 and Mcd7-42 were identified for resistance breeding with slow rusting resistance characteristics; TRS 0-30\% with MR and MS response, ACI 0-20, AUDPC less than $30 \%$.

Cultivars Boohai, Bichena, Quamy, Tate, Denbi, Worer, Toltu, Mukuye, Mangudoand other 119 landraces had TRS 31 to $50 \%$, ACI values ranging from 21 to 40 and rAUDPC between 31 and $70 \%$ and were regarded as moderately slow rusting resistance cultivars. However, the rest 99-durum wheat genotypes had no slow rusting resistance. 
The slow rusting and moderately slow rusting durum wheat genotypes identified in this study are expected to possess genes for varying degrees of slow rusting and could be useful for further exploitation in durum wheat improvement programs. [39] have also reported that genotypes, which have high and moderate slow rusting resistance could have durable resistance controlled by more than one gene that can serve as good parents for resistance breeding.

In this study, two hundred durum landraces evaluated for adult plant resistance and only eighty-eight landraces found moderately resistance, but all others found susceptible to the prevailed leaf rust isolates; such highly susceptibility of Ethiopian durum landraces for leaf rust also previously reported [40].

\section{CONCLUSIONS}

Evaluated durum wheat varieties and landraces showed variations in the level of Adult plant resistance, implying that there could be some diversity in the number of genes involved and on the size of their effect in conferring those types of resistance.

High yielding cultivars of durum wheat that is nearly immune to leaf rust could be developed by accumulating four to five slow rusting resistance genes through intercrossing parents that showed intermediate disease levels. Several adult plant resistances of durum cultivars identified in this study are being utilized for durable resistance in Ethiopian durum wheat improvement program. However, furthest testing for stability over years and locations for leaf rust along with other desirable characters required.

\section{REFERENCES}

[1]. FAO (Food and Agriculture Organization). 2015. Food Balance Sheets. FAOSTAT. (http://faostat.fao.org/download/FB/FBS/E).

[2]. Wageningen FSC (Wageningen University Food Security center). 2016. Multi-level mapping and exploration of Wheat production and consumption and their potential contribution to alleviation of poverty, malnutrition, and gender inequality. Final report, Nezerland.

[3]. REAP (Research for Ethiopia's Agriculture policy).2015. The wheat supply chain in Ethiopia, patterns, trends, and policy options. Addis Ababa, Ethiopia.

[4]. Rosegrant. 2010. Global food demand, supply, and price prospects to 2050. USDA,Washington, DC. (http://www.fas.usda.gov/data/.

[5]. Tilman, D., P., Reich, J., Knops, D., Wedin, T., Mielke.2001. Diversity and productivity in a long term grassland experiment. Science, 294:843-845.

[6]. Teklu, Y.,K. Hammer. 2008. Diversity of Ethiopian durum wheat germplasm: breeding opportunities for improving grain yield potential and quality traits. Plant genetic resource conservation, 7:1 8.

[7]. Klindworth, D.J., Miller, Y., Jin, S. Xu.2007. Chromosomal of genes for stem rust resistance in monogenic lines derived from durum wheat accession ST464. Crop Sciences, 47: 1012-1013.

[8]. CSA (Central Statistical Agency). 2017. Agricultural Sample Survey 2015-16. Volume VII: report on Crop and Livestock Product Utilization. Addis Ababa.

[9]. Ayele Badebo, Eshetu Bekele, Berhanu Bekele, Bekele Hundie and Melaku Degefu. 2008. Review of two decades of research on diseases of small cereal crops.Pp. 375-429. Proceedings of the $14^{\text {th }}$ Annual Conference of the Plant Protection Society of Ethiopia (PPSE), December 19-22, 2006, Addis Ababa, Ethiopia.

[10]. Shimelis, H.A. and Z.A. Pretorius. 2005. Leaf and stripe rust resistance among Ethiopian grown wheat lines. Ethiopian Journal of Sciences, 28: 23-32.

[11]. Ordonez, M.E., S.E., German, and J.A. Kolmer. 2010. Genetic differentiation within the Puccinia triticina population in South America and comparison with the North American population suggests common ancestry and intercontinental migration. Phytopathology, 100: 376-383.

[12]. Draz, I.S., Abou-Elseoud, M.S., Kamara, A.M., Alaa-Eldein, O.A., El-Bebany, A.F. 2015. Screening of wheat genotypes for leaf rust resistance along with grain yield. Annual Agricultural Sciences, 60:29-39. 
[13]. Bemnet, G., Ameha,Y., Alemayehu, Z., Jemanesh, K., and Tekalign, T. 2003. Fertilizer Neffects on yield and grain quality of durum wheat. Tropical Agriculture (Trinidad), 80(2):1 -6.

[14]. Peterson, R.F., A.B., Campbell, A.E., Hannah.1948. A diagrammatic scale for estimating rust intensity of leaves and stem of cereals. Canadian Journal of Research, 26:496-500.

[15]. WRB (World Reference Base), 2006. A framework for international classification, correlation and communication, world soil resource report 103. P.68. Rome, Italy.

[16]. Roelfs, A.P., R.P. Singh, and E.E. Saari. 1992. Rust Diseases of Wheat: Concepts and methods of disease management. Mexico, D.F.: CIMMYT.

[17]. Saari, E.E., and R.D., Wilcoxson. 1974. Plant disease situation of high yielding durum wheat in Asia and Africa, Annual Review. Phytopathology, 2:49-68.

[18]. Rajender Parsad, Abhishek Rathore and V.K Gupta.2003. Statstical package for augmented designs (SPAD). I.A.S.R.I Library Avenue, New Delhi.

[19]. Parlevliet, J.E., van Ommeren, A. 1975. Partial resistance of barely to leaf rust, Puccinia hordei,Relationship between field trials, micro plot tests, and latent period. Euphytica, 24:293-303.

[20]. Safavi, S.A. 2012. Evaluation of slow rusting parameters in thirty seven promising wheat lines to yellow rust. Technical Journal of English and Applied Science, 2:324- 329.

[21]. Nzuve, F.M., Bhavani, S., Tusiime, G., Njau, P., Wanyera, R. 2012. Evaluation of bread wheat for both seedling and adult plant resistance to stem rust. African Journal of Plant Sciences,6:426-432.

[22]. Parlevliet, J.E. 1988. Strategies for the utilization of partial resistance for the control of cereal rust. pp. 48-62. In: Rajaram, S., Simmonds, N.W. (eds.), Breeding Strategies for Resistance to the Rusts of Wheat. Mexico, D.F., CIMMYT.

[23]. Ali, S. Jawad, S. Shah, A. Ibrahim, M. 2007. Assessment of wheat breeding lines for slow yellow rusting (Puccinia striformis west. tritici). Pakistanian Journal of Biological Sciences, 10:3440-3444.

[24]. Li ZF, Xia XC, He ZH, Li X, Zhang LJ, Wang HY, Meng QF, Yang WX, LiG Q, Liu DQ. 2010. Seedling and slow rusting resistance to leaf rust in Chinese wheat cultivars. Journal of Plant Diseases, 94:45-53.

[25]. Safavi, S.A., Ahari, A.B., Afshari, F., Arzanlou, M. 2013. Slow rusting resistance in Iranian barley cultivars to Puccinia striiformis f. sp. hordei. Journal of Plant Protection Research,53:6-11.

[26]. Tabassum, S.2011. Evaluation of advance wheat lines for slow yellow rusting (Puccinia striiformis f. sp. tritici). Journal of Agricultural Sciences, 3:239-249.

[27]. Ali, S. Shah, A. Khalil, H. Raman, H. Maqbool, K. Ullah, W. 2009. Partial resistance to yellow rust in introduced winter wheat germplasm at the north of Pakistan. Australia Journal of Crop Sciences,3:37-43.

[28]. Pathon. A.K., Park, R.F. 2006. Evaluation of seedling and adult plant resistance to leaf rust in European wheat cultivars. Euphytica, 149:327-342.

[29]. Van der Plank, J.E.1963. Plant diseases. Epidemic and Control. Academic Press, New York. pp. 17-27.

[30]. Brown W.M.J., Hill, J.P., Velasco, V.R. 2001. Barley yellow rust in North America Annu. Rev. Phytopathology, 39:367-384.

[31]. Kaur, J., Bariana, H.S. 2010. Inheritance of adult plant stripe rust resistance in wheat cultivars Kukri and Sunco. Journal of Plant Pathology, 92:391 -394.

[32]. Singh, R.P., Huerta-Espino, J.,William, H.M. 2005. Genetics and breeding for durable resistance to leaf and stripe rusts in wheat. Turky Journal of Agriculture, 29:121 -127.

[33]. Ali, S., Shah S.J.A., Maqbool, K. 2008. Field-based assessment of partial resistance to yellow rust in wheat germplasm. Journal of Agriculture and Rural Development, 6:99-106. 
[34]. Schafer, J.F., Roelfs, A.P. 1985. Estimated relation between numbers of urediniospores of Puccinia graminis tritici and rates of occurrence of virulence. Phytopathalogy, 75:749-750.

[35]. Netsanet Bacha Hei. 2016. Evaluation of wheat cultivars for slow rusting resistance to leaf rust (Puccinia trticina Eriks) in Ethiopia. African Journal of Plant Sciences, 11(2): 23-29.

[36]. Shah, S.J.A., Imtiaz, M., Hussain, S. 2010. Phenotypic and molecular characterization of wheat for slow rusting resistance against Puccinia striiformis Westend. f.sp. tritici. Journal of Phytopathology, 158:393-402.

[37]. Freedman J, Mackenzie DR .1992. Disease progress curves, their mathematical description and analysis to formulate predictors for loss equations. pp. 37-48. In: Teng PS (ed.) Crop loss assessment and pest management. International Book Distributing Co., Lucknow, India.

[38]. Singh, D., R.F., Park,R.A., McIntosh.2007. Characterization of wheat leaf rust resistance gene Lr34 in Australian wheats using components of resistance and the molecular marker Lr34. Australian Journal of Agricultural Research, 58:1106-1114.

[39]. Singh, R.P., William, H.M., Huerta-Espino, J., Rosewame, G. 2004. Wheat rust in Asia: meeting the challenges with old and new technologies. New directions for a diverse planet .pp.1 -13. In: Fischer, T., Turner, N., Angus, J., McIntyre, L., Robertson, M., Borrell, A., Lloyd, D. (eds.), Proceeding of $4^{\text {th }}$ International Crop Science Congress. 26 September-1 October 2004. Brisbane, Australia.

[40]. Yesh Andenow, Mengistu Hulluka, Belay, G., and Tesemma, T. 1997. Resistance and tolerance to leaf rust in Ethiopian tetraploid wheat landraces. Plant Breeding, 116:533-536. 